ARTICLE

\title{
Aggravation of reactive nitrogen flow driven by human production and consumption in Guangzhou City China
}

Yue Dong (1) ${ }^{1}$, Linyu Xu (D) ${ }^{1 凶}$, Zhifeng Yang ${ }^{1}$, Hanzhong Zheng ${ }^{1} \&$ Lei Chen ${ }^{1}$

Human activities reshape the global nitrogen (N) cycle and affect environment and human health through reactive nitrogen $(\mathrm{Nr})$ loss during production and consumption. In urbanized regions, the $\mathrm{N}$ cycle is greatly mediated by complex interactions between human and natural factors. However, the variations in sources, magnitude, spatiotemporal patterns and drivers of $\mathrm{Nr}$ flows remain unclear. Here we show by model simulations, anthropogenic perturbations not only intensify $\mathrm{Nr}$ input to sustain increasing demands for production and consumption in Guangzhou city, China, but also greatly change the Nr distribution pattern in the urban system, showing a substantial $\mathrm{Nr}$ enrichment in the atmosphere and a relatively low retention capacity of $\mathrm{Nr}$ in the terrestrial system. Our results highlight the strong anthropogenic effect of urban systems on the $\mathrm{N}$ cycle to suggest sustainable human activity changes to harmonize the relationship between $\mathrm{Nr}$ behaviors and human drivers.

\footnotetext{
${ }^{1}$ State Key Joint Laboratory of Environmental Simulation and Pollution Control, School of Environment, Beijing Normal University, No. 19, Xinjiekouwai Street, Haidian District, Beijing 100875, China. ${ }^{凶}$ email: xly@bnu.edu.cn
} 
$\mathrm{N}$ itrogen $(\mathrm{N})$ is an essential element for all biological tissues, and the $\mathrm{N}$ cycle is one of the main biogeochemical cycles that can have a substantial and wide-ranging impact on the ecological environment ${ }^{1-3}$. Human activities have greatly changed the global $\mathrm{N}$ cycle and increased the creation of reactive nitrogen $(\mathrm{Nr})$ since Haber and Bosch succeeded in artificially synthesizing ammonia ${ }^{4,5}$. Influenced by strong anthropogenic effects, urban systems (especially megalopolises) have played a significant role in the tremendous changes in $\mathrm{Nr}$ creation and the $\mathrm{N}_{\text {cycle }}{ }^{6}$. A substantial body of research has shown that the amount of circulating $\mathrm{Nr}$ in cities is several times higher than that in surrounding non-urban ecosystems ${ }^{7,8}$. The relatively high demand for food, industrial goods, and energy due to urban life has driven high-throughput food $\mathrm{N}$ production in rural areas, led to massive industrial $\mathrm{N}$ fixation, and caused the release of organic $\mathrm{N}$ from fossil fuels. However, only a small proportion of anthropogenic $\mathrm{Nr}$ can be used efficiently by humans, and most $\mathrm{Nr}$ is lost or accumulated in the environment ${ }^{9}$. The intensification of $\mathrm{Nr}$ release into the environment has had negative effects on both the ecosystem and human health ${ }^{10}$, such as stratospheric ozone depletion $^{11}$, acid rain $^{12}$, water eutrophication ${ }^{11,12}$, biodiversity loss $^{13}$, and human heath impairment ${ }^{11}$.

The former $\mathrm{N}$ budget has been studied at the global ${ }^{14}$, national ${ }^{15}$ and regional ${ }^{16,17}$ levels. Compared with large scales, in urban regions, the $\mathrm{N}$ cycle is greatly mediated by complex interactions between human and natural factors, resulting in variations in sources, magnitude and spatiotemporal patterns ${ }^{18,19}$. Some urbanscale studies have mainly focused on specific aspects of the $\mathrm{N}$ balance in natural and socioeconomic systems, such as the cycling process of nutrients between urban areas and farmland ${ }^{20}, \mathrm{~N}$ flow in urban food consumption ${ }^{21,22}$ and $\mathrm{N}$ metabolism network flow analysis ${ }^{23}$. However, a detailed and holistic approach to mapping the coupled human-natural urban $\mathrm{N}$ flow trajectory is still lacking. Notably, some important urban $\mathrm{N}$ flow fates driven by human production and consumption activities are not fully understood. For example, figuring out the fate of urban industrial $\mathrm{N}$ has been challenging. Research has shown that the fate of $26 \mathrm{Tg} \mathrm{N} \mathrm{y}$ retained worldwide remains unknown, though it is most likely related to the cycling process of industrial $\mathrm{N}^{12}$. Synthetic industrial $\mathrm{N}$ is difficult to decompose and tends to accumulate in human settlements ${ }^{4,14,24}$, thereby changing the pattern of $\mathrm{Nr}$ metabolism in modern cities, which may have a significant impact on the environment and human health. Moreover, further quantitative analysis of the driving effect of human activities on $\mathrm{Nr}$ creation in urban systems are needed. Studies investigating the impact of human interference on the $\mathrm{N}$ cycle at the national level or watershed scale could ignore some sudden hot spots and new pollution sources $^{15,25}$, such as the recent rapid growth of industrial $\mathrm{N}$ emissions in urban systems ${ }^{26}$, which could amount to a missed opportunity to develop abatement management strategies targeting these sources of pollution.

The primary purposes of this study are to develop a new coupled human-natural nitrogen flow analysis model at the urban scale and then use this model to investigate how the $\mathrm{N}$ flow originated, modified, and affected the environment in a typical megalopolis. The model core is based on the human activities of the $\mathrm{N}$ cycle and associated effect on various subsystems. The city of Guangzhou $\left(22^{\circ} 26^{\prime}-23^{\circ} 56^{\prime} \mathrm{N}, 112^{\circ} 57^{\prime}-114^{\circ} 03^{\prime} \mathrm{E}\right)$ was selected as the study area as it is one of the most dynamic economic cities in China and the Asia Pacific region and has a dense population with an intense level of human activity. Guangzhou is also an advanced manufacturing base and a modern service base with a global influence. Guangzhou spans $7434 \mathrm{~km}^{2}$ and, in 2015 , had a population of $1.35 \times 10^{7}$ and an average urbanization rate of $85.53 \% 27$. The gross domestic product (GDP) of this city was
1,810.04 billion yuan, which was divided among primary, secondary, and tertiary industries, accounting for $1.25,31.64$, and $67.11 \%$ of this amount, respectively ${ }^{27}$. The concentrated population, rapidly developed industry and massive fossil fuel combustion have all accelerated $\mathrm{Nr}$ creation and caused $\mathrm{N}$ pollution in water sources and the atmospheric environment ${ }^{28}$.

Based on the coupled human-natural $\mathrm{N}$ flow analysis model, we analyse the temporal (1995-2015) variations of the $\mathrm{N}$ balance with respect to sources, fluxes, and fates with uncertainty in Guangzhou. Specifically, we carry out a life cycle analysis of food $\mathrm{N}$ and industrial $\mathrm{N}$, which are dominated by human production and consumption, and the impacts of the $\mathrm{N}$ flow process on the environment are highlighted. We find that $\mathrm{Nr}$ input into the urban system is manifested in not only artificial intensification but also the change of the input structure. The massive dependence of the urban system on external agricultural $\mathrm{N}$-contained products results in more $\mathrm{N}$ pollution into surface water from consumption rather than production. The Haber-Bosch $\mathrm{N}$ fixation tends to generate industrial synthetic products for human consumption rather than fertilizers for agricultural use, thus leading to the durative accumulation of industrial $\mathrm{Nr}$ in human settlements. Anthropogenic perturbations greatly change the $\mathrm{Nr}$ distribution pattern in the urban system, showing a substantial $\mathrm{Nr}$ enrichment in the atmosphere and a relatively low retention capacity of $\mathrm{Nr}$ in the terrestrial system. Subsequently, using an extended Stochastic Impacts by Regression on Population, Affluence, and Technology (STIRPAT) model, we quantitatively assessed the impact of human activities on $\mathrm{Nr}$ creation in the urban system and identified strategies that can be implemented to maintain sustainable development. In the urban system, practical strategies to regulate $\mathrm{Nr}$ creation should be focused on reducing the negative effects of industrial $\mathrm{Nr}$, encouraging a reasonable and balanced dietary structure and reducing $\mathrm{N}$ loss during energy consumption.

\section{Results}

Temporal variation of the $\mathbf{N}$ balance. Based on a coupled human-natural urban $\mathrm{N}$ flow analysis, we found that $\mathrm{Nr}$ flows in a typical megalopolis have been artificially intensified to sustain the increasing demands for production and consumption with continuous $\mathrm{Nr}$ loss in the environment (Fig. 1). The detailed $\mathrm{N}$ fluxes among 12 subsystems can be found in Supplementary Figs. 1, 3-14.

Over the past two decades, the total annual $\mathrm{Nr}$ inputs in Guangzhou increased from $142.5 \mathrm{Gg}$ to $301.5 \mathrm{Gg}$ and showed slight fluctuation (Fig. 2a). Anthropogenic $\mathrm{Nr}$ creation (excluding natural BNF) continued to increase from $90.9 \mathrm{Gg}$ in 1995 and reached $180.0 \mathrm{Gg}$ in 2015 , contributing to $95.0 \%$ of the total $\mathrm{Nr}$ creation (BNF, HBNF, and $\mathrm{N}$ fixation during fossil fuel combustion) (Fig. 2b). The anthropogenic dominating inputs included trade imports, $\mathrm{N}$ fixation during fossil fuel combustion, and HBNF, which accounted for 37.1, 29.5, and 28.3\%, respectively. Fossil fuel combustion increased from $26.0 \mathrm{Gg}$ to 89.0 $\mathrm{Gg}$ due to the growing demand for industrial production and household utilization in the urban system. The input intensity of $\mathrm{Nr}$ fixation from fossil fuel combustion in Guangzhou in 2015 was $119.7 \mathrm{~kg} \mathrm{~N} \mathrm{ha}^{-1} \mathrm{y}^{-1}$, which was much greater than the value of all of China $\left(8.85 \mathrm{~kg} \mathrm{Nha}^{-1} \mathrm{y}^{-1}\right)^{15}$. HBNF was used to produce $\mathrm{N}$ fertilizers and other synthetic ammonia products (e.g., plastics, synthetic rubbers, synthetic fibers, detergents, drugs and other products). Our estimate of the HBNF input intensity in 2015 was $114.6 \mathrm{~kg} \mathrm{~N} \mathrm{ha}^{-1} \mathrm{y}^{-1}$, which was higher than the average value in China $\left(\sim 48.9 \mathrm{~kg} \mathrm{Nha}^{-1} \mathrm{y}^{-1}\right)^{29}$. Another important characteristic of $\mathrm{Nr}$ inputs in Guangzhou was the heavy reliance on external supplies, especially agricultural products. 


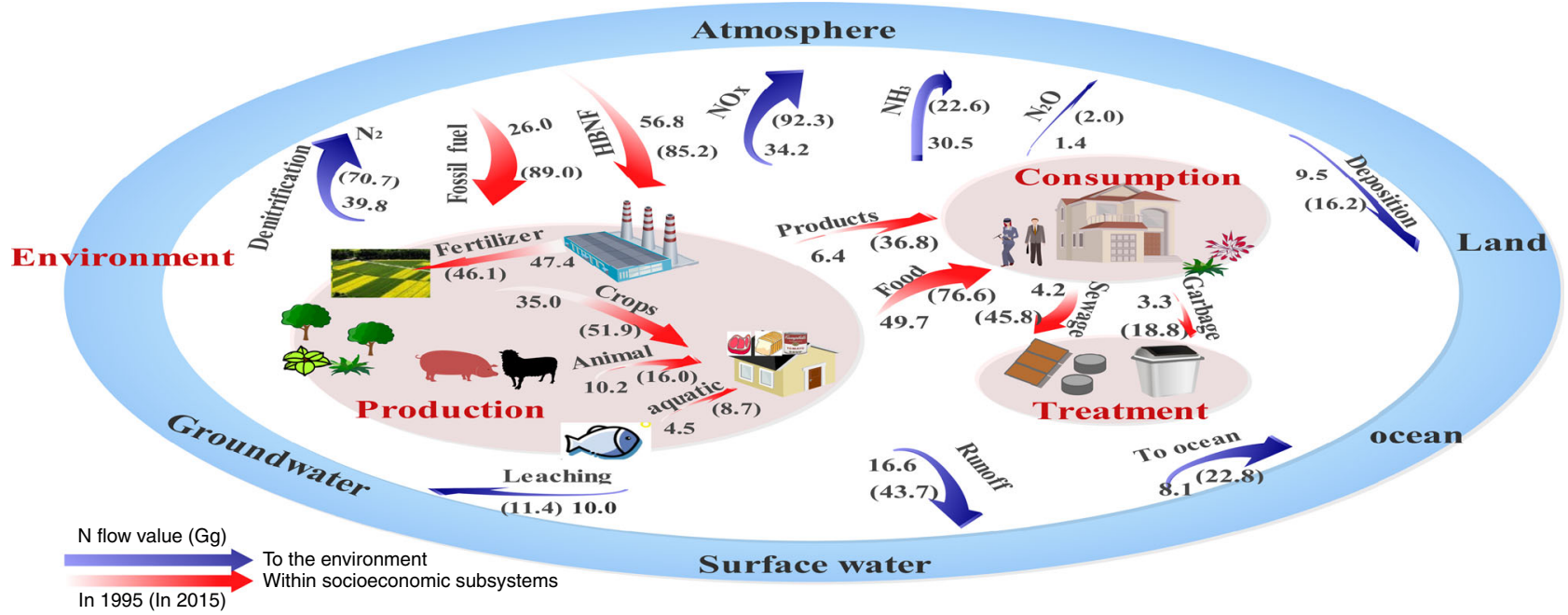

Fig. 1 Coupled human-natural urban nitrogen flow analysis in Guangzhou from 1995 to 2015 . N flows among production, consumption, treatment and environment process groups under anthropogenic perturbations. The numbers in brackets and out of brackets represent N fluxes in 2015 and 1995 , respectively. HBNF, Haber- Bosch $\mathrm{N}$ fixation. Units are in $\mathrm{Gg} \mathrm{N} \mathrm{y}{ }^{-1}$.
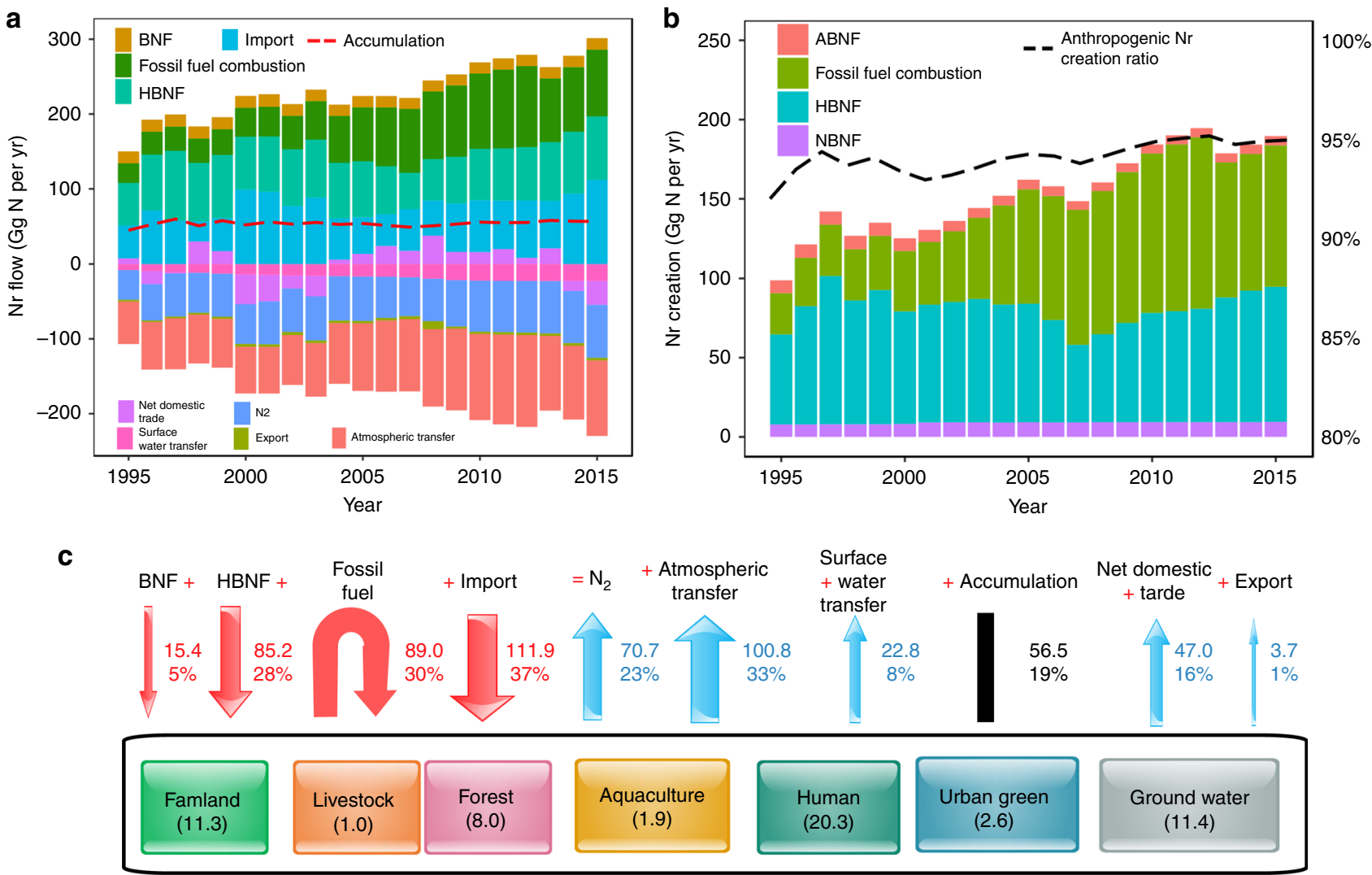

Fig. 2 Temporal variation of $\mathbf{N}$ balance in Guangzhou (Units are in $\mathbf{G g} \mathbf{N} \mathbf{~ y}^{\mathbf{- 1}}$ ). a The Nr input, output, and accumulation. $\mathbf{b}$ The $\mathrm{Nr}$ creation. $\mathbf{c}$ Schematic of $\mathrm{N}$ balance in 2015. ABNF, agricultural biological N fixation; HBNF, Haber- Bosch N fixation; NBNF, natural biological N fixation; Atmospheric transfer: Nr transfer to the surrounding areas; Surface water transfer: Nr transfer to oceans.

The total $\mathrm{N}$ outputs were $99.2 \mathrm{Gg}$ in 1995 and $245.0 \mathrm{Gg}$ in 2015, and approximately $50.4 \%$ was $\mathrm{Nr}$ that was ultimately discharged into the environment in 2015 (Fig. 2a, c). This large flux of $\mathrm{Nr}$ emissions could lead to serious atmospheric and hydrosphere problems. As a result of $\mathrm{Nr}$ inputs and outputs in the coupled human-natural urban system, the $\mathrm{Nr}$ accumulations were 44.7 $\mathrm{Gg}$ in 1995 and $56.5 \mathrm{Gg}$ in 2015. Human and farmland subsystems contributed to the greatest successive accumulation (Fig. 2a). In 2015, human subsystem contributed to $35.9 \%$ of the total accumulation, followed by farmland (20.0\%), forest (14.2\%), groundwater (20.2\%), urban green (4.6\%), aquaculture (3.4\%), and livestock (1.7\%) (Fig. 2c). Over the past two decades, Guangzhou gradually transformed into a typical advanced manufacturing and modern service-based city driven by 
substantial human consumption. Industrial synthetic products for human consumption resulted in an accumulation due to their long service lives. In contrast, in the entire country, farmland largely contributed to the $\mathrm{Nr}$ accumulation due to massive chemical fertilizer input and large cultivation scale 24 .

To ensure the robustness of the $\mathrm{N}$ flow results, we conducted a Monte Carlo simulation to test the propagation of input uncertainties into the successive and final results. The uncertainty results of key $\mathrm{N}$ flows in Fig. $2 \mathrm{c}$ are shown in Table 1, and the mean, $5^{\text {th }}$ and $95^{\text {th }}$ percentiles are provided. Small uncertainty was observed in the $\mathrm{N}$ flows derived from the official statistics. For example, $89.0 \mathrm{Gg}(66.7 \mathrm{Gg}, 113.0 \mathrm{Gg}) \mathrm{N}$ fixation from fossil fuel combustion in 2015 with range of $\sim 25 \%$ was estimated by consumption of all types of fossil energy and corresponding NOx emission factors. $\mathrm{Nr}$ accumulation was calculated as the difference between inputs and outputs, and all uncertainties in the inputs and outputs may be additive in $\mathrm{Nr}$ accumulation, e.g., $\mathrm{Nr}$ accumulation in the farmland subsystem was $11.3 \mathrm{Gg}(2.1 \mathrm{Gg}$, $22.5 \mathrm{Gg}$ ) with range of $\sim 90 \%$. Besides, we provided uncertainty analysis of partial $\mathrm{N}$ flows due to activities data and parameters respectively in Supplementary Fig. 15. Uncertainties due to parameters contributed more than that due to activity data to the full uncertainties. Moreover, we compared partial $\mathrm{N}$ flows with previous estimates from China and other cities to validate the rationality of the calculation results, which is provided in Supplementary Table 22 and Supplementary Discussion 2.

Industrial $\mathrm{Nr}$ fate analysis. Increased anthropogenic inputs of $\mathrm{Nr}$ provide more industrial products (including synthetic and organic products) to meet human demands. During production and consumption processes, a substantial proportion of $\mathrm{Nr}$ is lost to the environment. The synthetic products are mainly used as $\mathrm{N}$ fertilizer and feed for agricultural purposes and synthetic ammonia products (e.g., plastics, synthetic rubbers, synthetic fibers, detergents, drugs and other products) to meet human consumption demands. Synthetic industrial $\mathrm{Nr}$ is generally found near human settlements. Environmental and health problems driven by industrial $\mathrm{Nr}$ have become increasingly serious ${ }^{4,10}$. Here, we performed a life cycle analysis of industrial $\mathrm{N}$ to obtain a more holistic understanding of $\mathrm{N}$ fate from production to consumption in the urban system (Fig. 3).

The $\mathrm{Nr}$ flux in the industrial subsystem sharply increased from $125.2 \mathrm{Gg}$ in 1995 to $184.9 \mathrm{Gg}$ in 2015 primarily due to an increase in HBNF and N fixation through fossil fuel combustion. In 2015, $46 \%$ of $\mathrm{Nr}$ inputs into industrial production were used to support agricultural activities and human consumption, while residual $\mathrm{Nr}$ was discharged into the environment or transferred to the external system. The fossil energy input into the industrial system was substantial, resulting in the release of $83.6 \mathrm{Gg}$ of $\mathrm{NOx}$ emissions into the atmosphere in 2015 mainly caused by emissions from automobiles, aircraft, internal combustion engines, and industrial furnaces. In Guangzhou, the $\mathrm{NO}_{2}$ concentration $\left(47 \mu \mathrm{g} \mathrm{m}^{-3}\right)$ exceeded the acceptable maximum rate outlined by the second grade of the Ambient Air Quality Standards in China $\left(40 \mu \mathrm{g} \mathrm{m}^{-3}\right)$ in $2015^{28}$, leading to negative environment and human health effects. Therefore, controlling industrial $\mathrm{NOx}$ emissions is a vital and urgent issue in Guangzhou.

HBNF is one of the most important new $\mathrm{Nr}$ inputs into circulation in Guangzhou. HBNF increased from $56.8 \mathrm{Gg}$ in 1995 to $85.2 \mathrm{Gg}$ in 2015. In 1995, small quantities of HBNF entered the industrial subsystem to provide synthetic ammonia products for human consumption; the most important output from HBNF was fertilizer $\mathrm{N}$ (i.e., $52.3 \mathrm{Gg}, 92 \%$ of HBNF), most of which was designated for farmland use, which is very similar to the HBNF

\begin{tabular}{|c|c|c|c|}
\hline \multirow[t]{2}{*}{$\mathbf{N}$ balance } & \multicolumn{3}{|l|}{ Range } \\
\hline & Mean & 5th & 95th \\
\hline \multicolumn{4}{|l|}{ Inputs } \\
\hline BNF & 15.4 & 12.6 & 18.3 \\
\hline HBNF & 85.2 & 75.6 & 95.3 \\
\hline Fossil fuel & 89.0 & 66.7 & 113.0 \\
\hline Import & 111.9 & 88.3 & 135.2 \\
\hline \multicolumn{4}{|l|}{ Outputs } \\
\hline $\mathrm{N}_{2}$ & 70.7 & 52.8 & 87.4 \\
\hline Atmospheric transfer & 100.8 & 76.5 & 123.9 \\
\hline Surface water transfer & 22.8 & 11.1 & 34.6 \\
\hline Net domestic trade & 47.0 & 23.2 & 70.3 \\
\hline Export & 3.7 & 3.0 & 4.4 \\
\hline \multicolumn{4}{|l|}{ Accumulations } \\
\hline Farmland & 11.3 & 2.1 & 22.5 \\
\hline Livestock & 1.0 & 0.8 & 1.3 \\
\hline Forest & 8.0 & 5.3 & 10.6 \\
\hline Aquaculture & 1.9 & 0.1 & 4.1 \\
\hline Human & 20.3 & 10.5 & 29.4 \\
\hline Urban green & 2.6 & 1.7 & 3.5 \\
\hline Ground water & 11.4 & 8.9 & 16.8 \\
\hline
\end{tabular}

fate observed in China in 2010 (i.e., fertilizer $\mathrm{N}$ accounted for $87 \%$ of HBNF $)^{24}$. However, in 2015, synthetic ammonia products accounted for $\sim 41 \%$ of the HBNF input in Guangzhou, while the remaining $\sim 57 \%$ was associated with agricultural use, leading to the accumulation of synthetic ammonia products in the human subsystem. The total accumulation of synthetic ammonia products in the human system reached $18.0 \mathrm{Gg}$ in 2015 , which was approximately six times higher than that in $1995(3.1 \mathrm{Gg})$. The load of garbage treatment (mainly from synthetic ammonia waste) increased from $3.3 \mathrm{Gg}$ in 1995 to $18.8 \mathrm{Gg}$ in 2015 , most of which was recycled to the human subsystem.

Food $\mathrm{Nr}$ fate analysis. Figure 4 shows the life cycle analysis of food $\mathrm{Nr}$ fate from production and consumption in Guangzhou. Inputs of $\mathrm{Nr}$ to food production (i.e., including crops, livestock, and aquaculture products) increased from $100.1 \mathrm{Gg}$ to $167.8 \mathrm{Gg}$ from 1995 to 2015 mainly due to the growth of import products. Correspondingly, Nr inputs from fertilizer and ammoniated feed slightly declined from $52.3 \mathrm{Gg}$ to $51.5 \mathrm{Gg}$ during this 20-year period. To obtain food, a developed city such as Guangzhou relies on external input more than local production, resulting in relatively low $\mathrm{Nr}$ emissions and accumulations from agricultural production in the environment. In 2015, a total of $38.3 \mathrm{Gg}$ of $\mathrm{Nr}$ from food production was transferred to the environment, resulting in accumulations in the agricultural system $(14.2 \mathrm{Gg})$, emission to the atmosphere $(16.7 \mathrm{Gg})$, and discharge to the water $(7.4 \mathrm{Gg})$. In contrast to production, consumption by the dense population in the urban system greatly increased $\mathrm{Nr}$ emissions in the environment. In 2015, 76.6 Gg food $\mathrm{N}$ was input into the human subsystem, resulting in $56.3 \mathrm{Gg}$ released into the environment, $65.0 \%$ of which was discharged into surface water bodies. In urban systems, greater attention should be paid to $\mathrm{Nr}$ management in food consumption to reduce $\mathrm{Nr}$ losses.

Approximately $25 \%$ of the $\mathrm{Nr}$ input into the farmland was transferred as food to human consumption. The nitrogen use efficiency (i.e., NUE, which is calculated as the $\mathrm{Nr}$ contained in harvest crop products divided by the $\mathrm{Nr}$ inputs) of the food production system in the farmland was equivalent to that in China $^{30,31}$ but lower than that observed in North America ${ }^{32}$ and Europe $^{33}$, where it was typically above $50 \%$. Moreover, the 


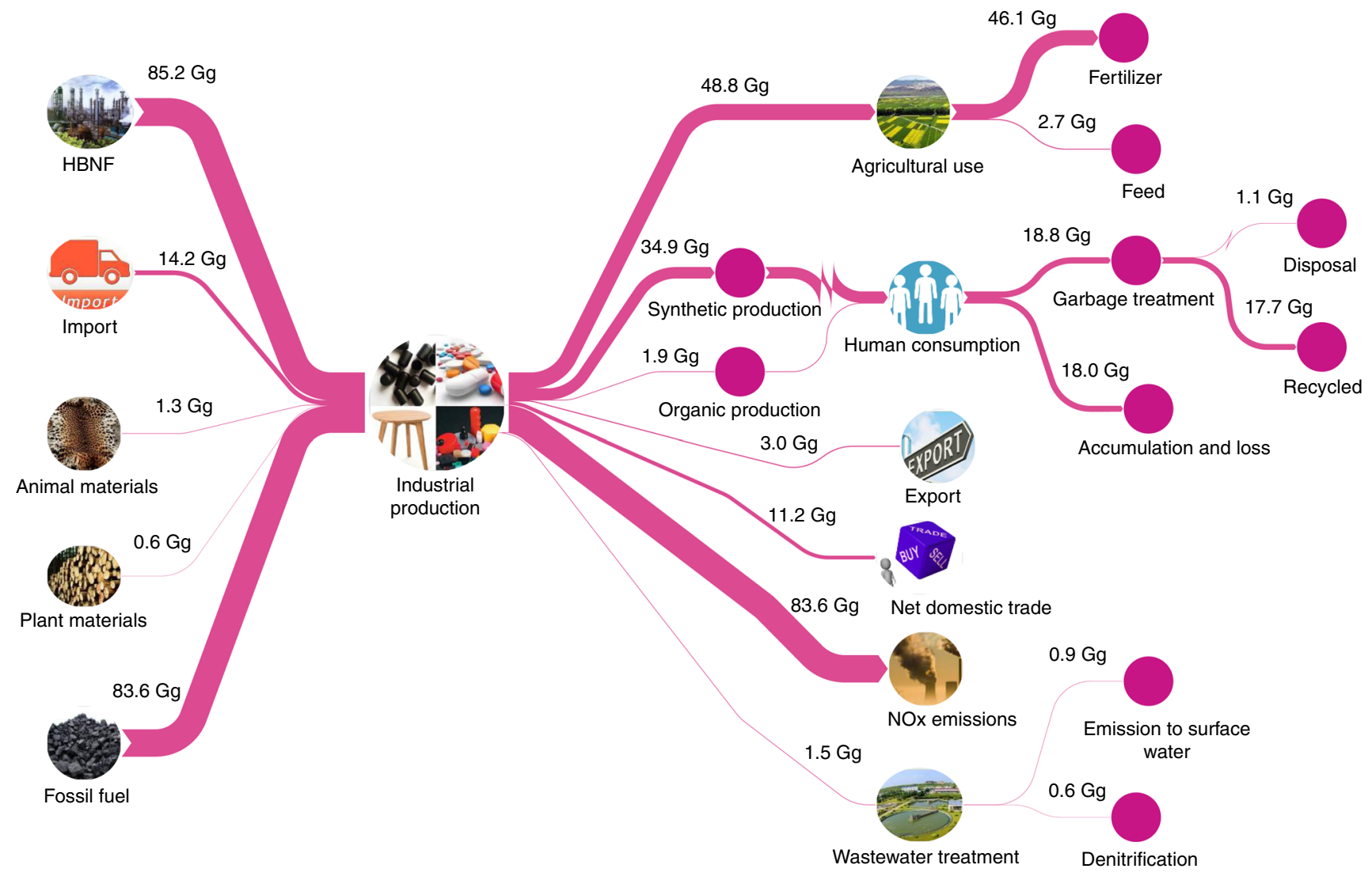

Fig. 3 Life cycle analysis of the industrial Nr fate of Guangzhou in 2015. Anthropogenic inputs of Nr through HBNF, import, agriculture materials and fossil fuel provide industrial products (including synthetic and organic products) to meet human demands, a fraction of $\mathrm{Nr}$ is for agriculture use and human consumption, the rest is transferred outside the system or lost to the environment. HBNF, Haber-Bosch N fixation. Units are in Gg N y ${ }^{-1}$.

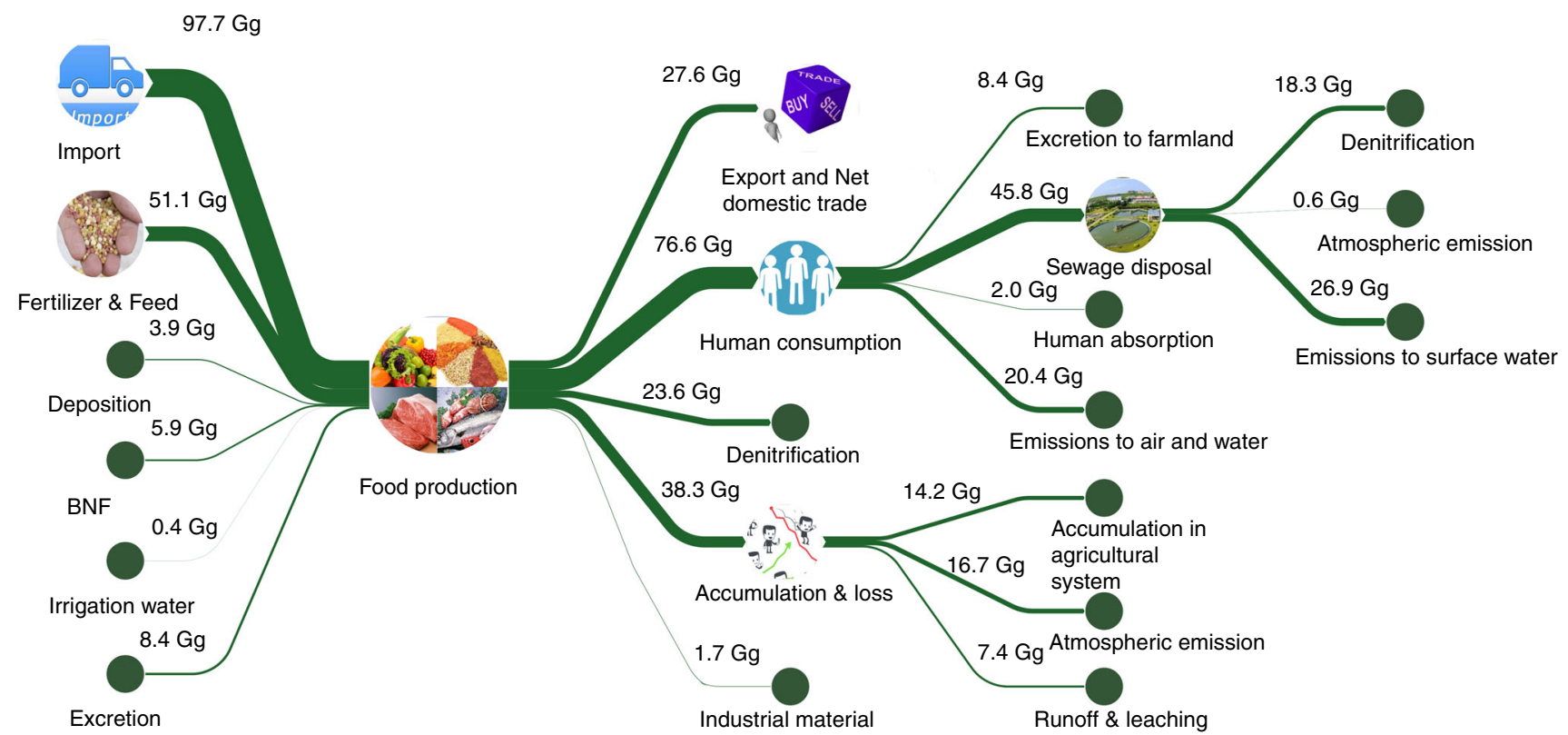

Fig. 4 Life cycle analysis of the food $\mathbf{N r}$ fate of Guangzhou in 2015. Inputs of Nr to food production include import, BNF, organic and chemical fertilizer, N deposition, feed, and irrigation water, a fraction of $\mathrm{Nr}$ is for human food consumption, the rest is transferred outside the system or lost to the environment. $\mathrm{BNF}$, biological $\mathrm{N}$ fixation; Units are in $\mathrm{Gg} \mathrm{N} \mathrm{y}^{-1}$. 
human absorption ratio of $\mathrm{Nr}$ to input declined from $4.4 \%$ in 1995 to $2.6 \%$ in 2015. Diets changed during the 20 -year period, and the ratio of grain protein to animal protein consumed by humans decreased from 2.4 to 2.1 .

In China, excreta has been used as fertilizer for centuries ${ }^{34}$. However, the farmland in the urban system is poorly coupled to the livestock and human subsystems, and the overall $\mathrm{N}$ recycling ratios of livestock and human excreta declined from 48 and $70 \%$ in 1995 to 42 and $11 \%$ in 2015, respectively. Previous studies have examined the entirety of China and explored the consequences of an increasing recycling rate of $\mathrm{N}$ from livestock and the human subsystem back to farmland, which shows a substantial reduction in $\mathrm{Nr}$ creation $^{24}$. Therefore, to increase the recycling of $\mathrm{Nr}$, it is necessary to improve decentralized stockbreeding management and the construction of waste disposal facilities in the urban system. Such improvements could ensure the sustainability of agriculture while promoting human health and the environment.

Nr environmental load characteristics. During the natural biogeochemical cycling of $\mathrm{N}, \mathrm{Nr}$ to atmosphere is primarily transformed into stable $\mathrm{N}_{2}$ through denitrification ${ }^{35}$. Our analysis demonstrated that in Guangzhou, approximately $23.4 \%$ of annual $\mathrm{Nr}$ inputs were denitrified as $\mathrm{N}_{2}$; the remainder was transferred to the environment and external system or accumulated in the subsystems. During the 20-year period, the increases in $\mathrm{Nr}$ emissions in the environment have been durative and extreme ranging from $83.3 \mathrm{Gg}$ in 1995 to $185.9 \mathrm{Gg}$ in 2012 with an annual growth rate of $7.2 \%$. From 2013 to 2015 , the rapid upward trend eased with an average level of $163.0 \mathrm{Gg}$ mainly due to lower NOx emissions. In 2013, the Chinese State Council implemented the Air Pollution Prevention and Control Action Plan ${ }^{36}$, which aimed to reduce emissions from power plants, industrial boilers, motor vehicles, and fugitive dust, thus encouraging low NOx emissions. The primary sources of atmospheric emissions were identified as $\mathrm{NOx}$, followed by $\mathrm{NH}_{3}$ and $\mathrm{N}_{2} \mathrm{O}$, which can cause gaseous pollution through atmospheric flow and secondary reactions, such as haze ${ }^{37}$. The change in NOx was the most significant as it was estimated to be $34.2 \mathrm{Gg}$ in 1995 and $92.3 \mathrm{Gg}$ in 2015 (Fig. 5a). After 2002, in particular, the release of NOx, mainly by fossil fuel combustion, increased sharply and suddenly, which is consistent with the increase in energy intensity during this period ${ }^{38}$. The main sources of NOx include fossil fuel combustion from industrial production, which accounted for $73.7 \%$ in 1995 and $90.6 \%$ in 2015 of the total NOx emission, followed by fossil fuel combustion of domestic consumption and straw burning. $\mathrm{NH}_{3}$ volatilization is mainly associated with the use of chemical fertilizers and biological excretion ${ }^{39}$. In Guangzhou, due to the reduction in farmland area, chemical fertilizer use contributed to a gradual decrease in $\mathrm{NH}_{3}$ emissions (Fig. 5b). In contrast, the increasingly dense population resulted in a considerable release of $\mathrm{NH}_{3}$ into the atmosphere. Moreover, $\mathrm{N}_{2} \mathrm{O}$ from denitrification contributed an increasing amount of $\mathrm{Nr}$ in the atmosphere, which is a powerful greenhouse gas ${ }^{40}$, revealing an increase of $1.4 \mathrm{Gg}$ to $2.0 \mathrm{Gg}$ over the past 20 years (Fig. 5c). Previous studies have shown that $\mathrm{N}_{2} \mathrm{O}$ is mainly derived from agricultural soil ${ }^{41}$, and our analysis demonstrated that in an urban system, nitrification and denitrification associated with sewage treatment processes can produce more $\mathrm{N}_{2} \mathrm{O}$ emissions, which accounted for $30.0 \%$ of the total $\mathrm{N}_{2} \mathrm{O}$ emissions in 2015 .

The $\mathrm{Nr}$ input into surface water was $17.2 \mathrm{Gg}$ in 1995 and $47.2 \mathrm{Gg}$ in 2015 , with $8.1 \mathrm{Gg}$ and $22.8 \mathrm{Gg}$ transferred to the ocean each year (Fig. 5d). Nr inputs from various sources greatly changed over the past twenty years. These changes were mainly driven by human consumption and discharge, which caused an increase in the fluvial transport of $\mathrm{N}$ and reflected an increase from $4.9 \mathrm{Gg}$ to $36.6 \mathrm{Gg}$ in domestic wastewater discharge of $\mathrm{N}$ to surface water during the 1995-2015 period. In the near future, with the advancement of urbanization and the improvement in living standards, the discharge of domestic wastewater will continue to increase. In contrast, agricultural $\mathrm{Nr}$ emissions into surface water in Guangzhou significantly decreased, and in 2015, Nr transferred to rivers from farmland, livestock, and aquaculture subsystem only accounted for $7.8,6.1$, and $1.7 \%$ of the total $\mathrm{Nr}$ inputs into rivers.

Human drivers analysis. An OLS regression estimate of the extended STIRPAT model was used to examine the contributions of four selected individual factors (i.e., population, dietary choice, energy intensity, and industrial level) to anthropogenic $\mathrm{Nr}$ creation. The regression coefficients of all explanatory variables were significant, and the $\mathrm{R}$ square was 0.940 , indicating a good reliability for goodness-of-fit (Table 2, Supplementary Fig. 16 and Supplementary Discussion 1).

The results showed that population, industrial level, dietary choice, and energy intensity together contributed $\sim 94 \%$ to the anthropogenic $\mathrm{Nr}$ creation changes in Guangzhou. Over the past two decades, the population in Guangzhou increased by $2.4 \%$ per year, resulting in a $2.2 \%$ annual increase in anthropogenic $\mathrm{Nr}$ creation with a contribution rate of $33 \%$. The population has the greatest potential impact on $\mathrm{Nr}$ creation change, which is consistent with the result in China ${ }^{15}$. The industrial level increased by an average of $0.4 \%$ per year, was strongly correlated with $\mathrm{Nr}$ creation, and showed a 30\% contribution rate. The increase in human production and consumption leads to greater levels of $\mathrm{Nr}$ creation from HBNF. Sustainable approaches are needed to reduce the negative effects of the increase in industrial $\mathrm{Nr}$ products. In Guangzhou, diets have shifted towards a focus on more animal protein, while the $\mathrm{N}$ intake from animal food is increasing at an annual rate of $0.46 \%$. Dietary changes resulted in a $1.2 \%$ annual increase in anthropogenic $\mathrm{Nr}$ creation with a contribution rate of $18 \%$. A reasonable and balanced dietary structure is encouraged. Energy consumption per unit of GDP during this period rapidly declined by $3.53 \%$ per year, which negatively contributed to a $13 \%$ change in $\mathrm{Nr}$ creation. Therefore, promoting efficiency in energy use has a significant effect on the reduction of atmospheric $\mathrm{Nr}$ emissions.

\section{Discussion}

$\mathrm{Nr}$ input into the urban system is manifested in not only artificial intensification but also the change of the input structure. An important characteristic of $\mathrm{Nr}$ input in Guangzhou was heavy reliance on external supplies, especially agricultural products. Consequentially, the substantial increase in $\mathrm{Nr}$ creation by $\mathrm{N}$ contained production in other locations was caused by the urban system. The massive dependence of the urban system on external $\mathrm{N}$-contained products resulted in an embodied $\mathrm{N}$ pollution transfer from developed consumptive cities to production regions through trade ${ }^{10}$. Moreover, the dependence on external food input resulted in relatively low $\mathrm{Nr}$ emissions from agricultural production. In contrast to production, consumption by the dense population in the urban system greatly increased $\mathrm{Nr}$ emissions to the environment, especially to the surface water. In $2015, \mathrm{Nr}$ transfer to rivers from domestic wastewater accounted for $78 \%$ of the total $\mathrm{Nr}$ input into rivers, indicating that in a developed urban system, $\mathrm{Nr}$ transfer to rivers is primarily due to human consumption rather than productive and natural processes. The situation differed with respect to the $\mathrm{Nr}$ sources of the water in China, where $\mathrm{Nr}$ in the water was mainly derived from processes associated with livestock production and the loss of $\mathrm{N}$ fertilizer ${ }^{29}$.

In China, HBNF contributed $45.9 \mathrm{Tg} \mathrm{N}$ to produce chemical fertilizers in 2010, which is approximately $87 \%$ of the total 

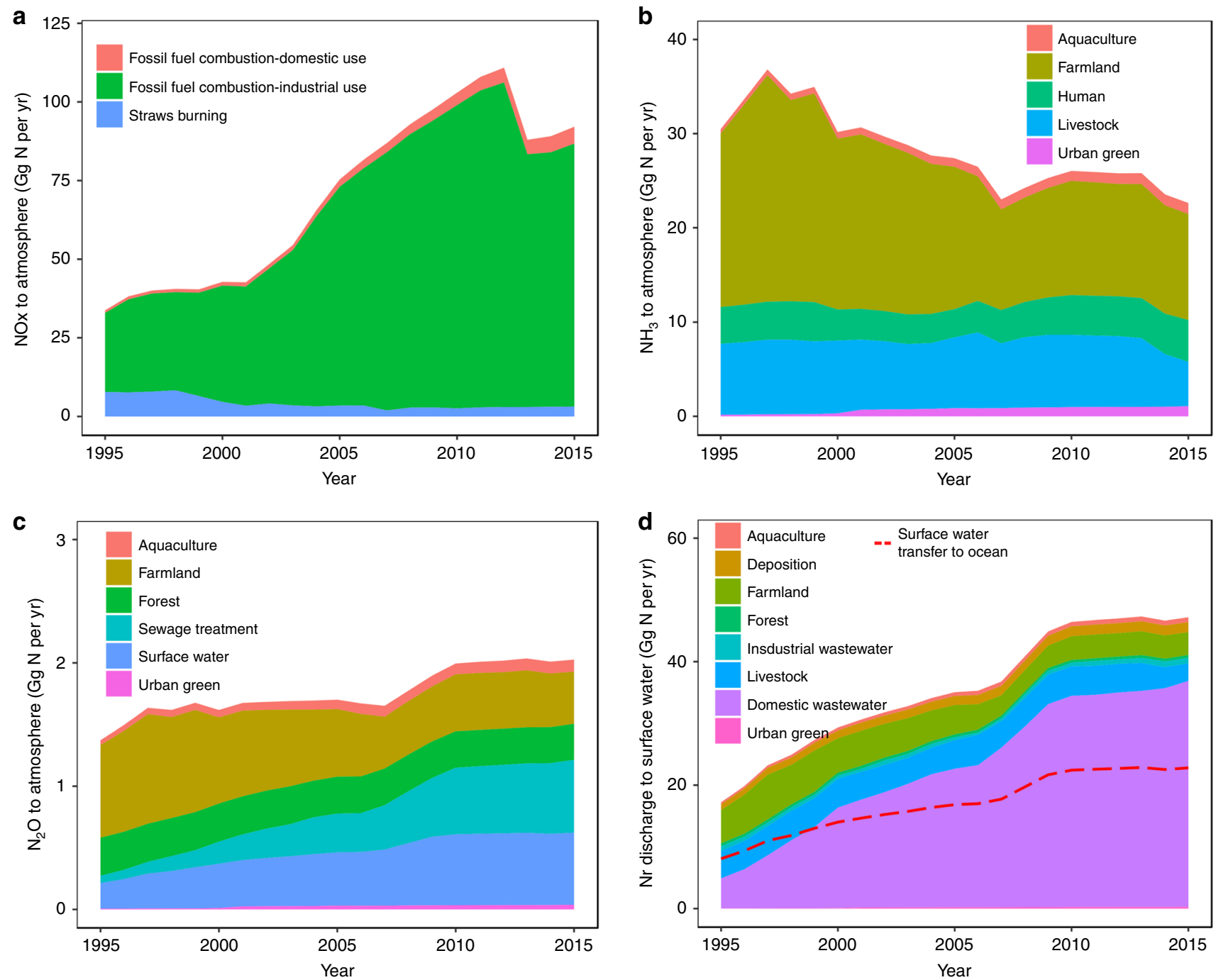

Fig. 5 Temporal variation in Nr environmental load characteristics in Guangzhou from $\mathbf{1 9 9 5}$ to 2015. a NOx emissions to the atmosphere from fossil fuel combustion and straws burning; b $\mathrm{NH}_{3}$ emissions to the atmosphere from aquaculture, farmland, human, livestock and urban green subsystems; c $\mathrm{N}_{2} \mathrm{O}$ emissions to the atmosphere from aquaculture, farmland, forest, sewage disposal, surface water and urban green subsystems; $\mathbf{d}$ Nr discharge into surface water from aquaculture, atmosphere, farmland, forest, industry, livestock, sewage disposal and urban green subsystems.

Table 2 Contributions of socioeconomic factors to changes in anthropogenic Nr creation.

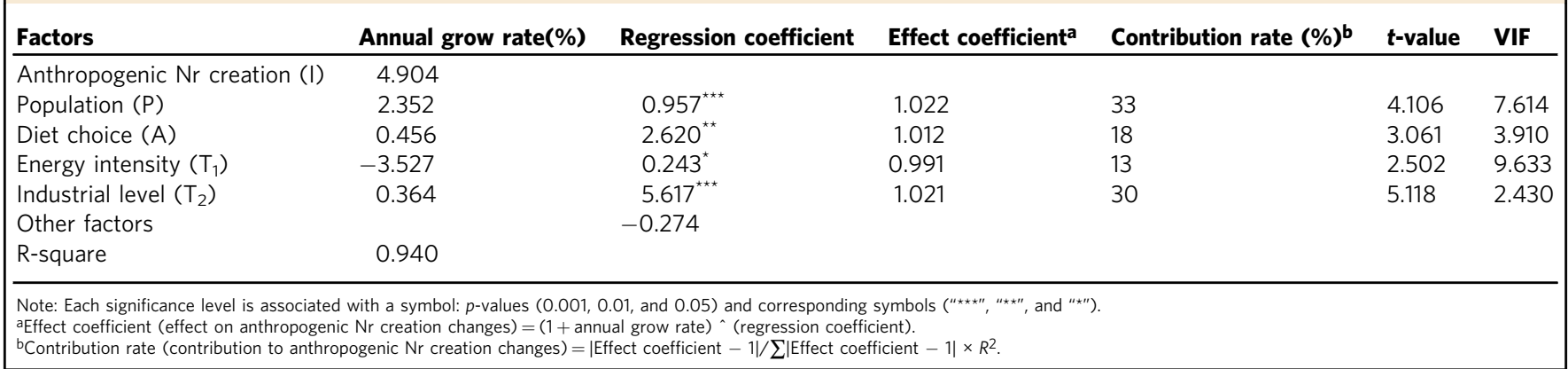

$\mathrm{HBNF}^{15}$. However, in Guangzhou, this ratio declined from 92 to $57 \%$ during 1995-2015, in contrast, HBNF contributing to other synthetic ammonia products sharply increased from 6 to $41 \%$. HBNF tended to be used to generate synthetic ammonia products for human consumption rather than fertilizers for agricultural use in the urban system, thus resulting in the accumulation of synthetic ammonia products in human settlements. Synthetic ammonia products (e.g., fibers, plastics, rubbers, and dyes) are difficult to decompose, leading to the durative total amount of industrial $\mathrm{Nr}$ accumulation being much greater than the annual accumulation, which could contribute to explain the unknown $\mathrm{Nr}$ pool worldwide cited by Schlesinger ${ }^{12}$. Long-term cumulative 
industrial $\mathrm{Nr}$ which delays $\mathrm{Nr}$ release to the environment could induce the legacy effect of industrial $\mathrm{Nr}^{41}$. This type of legacy effects may cause great threats to environmental and human health, for instance, harmful $\mathrm{Nr}$ compounds released from paint and dye decomposition ${ }^{42}$.

The fate tracking of $\mathrm{Nr}$ introduced into the urban system showed that approximately 23.4 and $16.8 \%$ of the annual $\mathrm{Nr}$ input was denitrified to $\mathrm{N}_{2}$ and outputted through trade, respectively, while the remainder was transferred to the environment or accumulated in the subsystems (Fig. 2). Approximately $33.4 \%$ was transferred to the atmospheric environment as $\mathrm{NOx}, \mathrm{N}_{2} \mathrm{O}$ and $\mathrm{NH}_{3}, 7.7 \%$ was discharged into surface water, and the remaining $18.7 \%$ of $\mathrm{Nr}$ accumulated in terrestrial systems (including farmland, livestock, forest, aquaculture, human, ground water and urban green subsystems). Differing from our results, a national study showed that the terrestrial system was the main $\mathrm{N}$ pool in China, accounting for over twothirds of the annual $\mathrm{N}$ accumulation, followed by water bodies and the atmosphere ${ }^{15}$. Worldwide, in the 1990s, the fate of $\mathrm{Nr}$ input was relatively well know; $~ 18 \%$ was transferred to coastal systems via rivers, $\sim 13 \%$ underwent atmospheric transfer and was eventually deposited into oceans, and $\sim 22 \%$ accumulated in terrestrial systems ${ }^{3}$. Compared with global and national studies, we found that the anthropogenic perturbations greatly changed the $\mathrm{Nr}$ distribution pattern in the urban environment, showing substantial $\mathrm{Nr}$ enrichment in the atmosphere, resulting in serious atmospheric $\mathrm{Nr}$ pollution, especially NOx pollution. In the atmosphere, tropospheric NOx can lead to an increase in the rate of asthma and other respiratory illnesses, particularly in children and other vulnerable populations ${ }^{43}$. Furthermore, analytic results of atmospheric PM2.5 sources have shown that NOx gaseous pollutants in motor vehicle exhausts accounted for a large proportion ${ }^{44,45}$. In contrast, the $\mathrm{Nr}$ accumulation in the terrestrial system was much lower than the national level, indicating a reduced capacity to retain $\mathrm{Nr}$ input.

Through understanding the socioeconomic driving effect on anthropogenic $\mathrm{Nr}$ creation, we focus on sustainable human activity changes to harmonize the relationship between $\mathrm{Nr}$ behaviors and human drivers. First, sustainable approaches are needed to reduce the negative effects of industrial Nr. Improving treatment technology could reduce toxic $\mathrm{Nr}$ discharge after the production of industrial $\mathrm{Nr}$ products. For example, using nano$\mathrm{TiO}_{2}$ photocatalysis to treat dyes could degrade toxic dyes compounds into non-toxic inorganics effectively such as $\mathrm{NH}_{4}{ }^{+}-\mathrm{N}$, $\mathrm{NO}_{3}-\mathrm{N}^{46}$. Besides, increasing reuse rate of newly industrial $\mathrm{Nr}$ products could reduce garbage generation, further reduce the negative effect caused by legacy effect ${ }^{47}$, such as garbage siege ${ }^{48}$. Moreover, improving production technology of $\mathrm{Nr}$ products could reduce toxic $\mathrm{Nr}$ release when they are produced, used or abandoned. For example, using non-diazo-coupling method to synthesize azo dyes (e.g. methyl red) could reduce toxic nitrogenous compounds discharge during the production ${ }^{49}$. Second, a reasonable and balanced dietary structure is encouraged. Compared with grain protein diets, the consumption of animal protein is expected to cause more $\mathrm{N}$ losses to the environment ${ }^{50}$. Diet interventions that prevent an increase in the consumption of animal protein could reduce $\mathrm{Nr}$ input. Third, reducing $\mathrm{N}$ loss during energy consumption is essential. Promoting efficiency in energy use is extremely important to relieve the increase in $\mathrm{N}$ fixation during fossil fuel combustion and the emission of $\mathrm{NOx}^{51}$. The expanding use of new energy to shift away from fossil fuel consumption is imperative ${ }^{16}$. Given the unique and intense extent of $\mathrm{Nr}$ problems in urban systems, these approaches could effectively support the public and decision makers and ultimately yield more sustainable policies.

\section{Methods}

Dataset. Data were collected from three sources: a number of national, provincial, and urban statistical databases, including the China Statistical Yearbook on Environment (1995-2015), the China City Statistical Yearbook (1995-2015); Guangdong Statistical Yearbook (1995-2015), Guangzhou Statistical Yearbook (1995-2015), Guangzhou Environmental Quality Report (1995-2015); provincial and urban survey and planning documents, such as Guangzhou General Plans for Land Use (2006-2020), and the Guangdong Forest and Grassland Resources Inventory; and existing research results and methodologies.

Urban nitrogen flow analysis model. In this study, the $\mathrm{Nr}$ inputs to the system are a result of $\mathrm{N}$ fixation through biology, the Haber-Bosch process, fossil fuel combustion, and imports. In addition, the $\mathrm{Nr}$ outputs of the system occur when $\mathrm{Nr}$ is reduced to $\mathrm{N}_{2}$ or lost to external systems. Within the boundary, we constructed the $\mathrm{N}$ flow analysis model (Supplementary Fig. la and Supplementary Method 1), which divided the system into four process groups, including production, consumption, treatment, and environment, based on the $\mathrm{N}$ fate as modified by human activity. The production group, including farmland, urban green, livestock, forest, aquaculture, and industry subsystems, can process the fixed $\mathrm{N}$ input into the food chain, biomass and synthetic products. The consumption group largely focuses on human subsystems. Treatment refers to a group, including sewage and garbage disposal subsystems, that can treat waste $\mathrm{Nr}$ and eliminate its negative impact. The environment group includes atmosphere, surface water, and groundwater subsystems. Each subsystem can be viewed as a dynamic unit and a reservoir of Nr. All $\mathrm{Nr}$ input from the external system will access one or several subsystems, recycle among the 12 subsystems, or output to the outside.

Based on the principle of the conservation of mass, the $\mathrm{N}$ balance $\mathrm{e}^{52}$ in the whole system and each subsystem is expressed using the following equation:

$$
\sum A C_{k}=\sum I N_{i}-\sum O U T_{j}
$$

where $I N_{i}$ and $O U T_{j}$ represent the $\mathrm{Nr}$ inputs and outputs, respectively; and $A C_{k}$ represents $\mathrm{Nr}$ accumulation.

More precisely, the coupled human-natural urban nitrogen flow analysis model comprises two interrelated models, namely, the Full Nitrogen Flow Analysis (FNFA) model and the Nitrogen Network Calculator (NNC). Based on the substance flow analysis, the FNFA model was developed to characterize the dynamics of the $\mathrm{N}$ fate and flux across 12 subsystems (i.e., farmland, urban green, livestock, forest, aquaculture, industry, human, sewage disposal, garbage disposal, surface water, ground water, and atmosphere) throughout the system. The detailed model framework is shown in Supplementary Fig. 1b and Supplementary Method 2. The calculation of input, output and accumulation in each subsystem were described in Supplementary Tables 1-12. Furthermore, the activity data and parameters information in each input, output and accumulation were interpreted in Supplementary Tables 13-21.

The NNC was proposed as a method that could help organize and synthesize large amounts of information with uncertainty using $\mathrm{R}$ software when carrying out the $\mathrm{N}$ balance calculation ${ }^{53}$. The detailed NNC models are shown in Supplementary Fig. 2 and Supplementary Method 3. By combining the FNFA and NNC models, the N flow analysis of the coupled human-nature urban system automatically produced massive, fast, and synchronous calculations of $\mathrm{N}$ fluxes and their interactions.

For uncertainty analysis, we conducted the Monte Carlo simulation to test the propagation of input uncertainties into the successive and final results. The variables were attributed continuous distributions instead of single point estimate. According to the data quality, different continuous distributions were applied and different coefficients of variation (CVs) were set. We classified the CVs of variables into three grades: high, moderate, and low reliabilities, which were assumed to have the values of $0.1,0.2$, and 0.3 , respectively ${ }^{54}$. The simulation model ran 10,000 trials by randomly selecting values from the input distributions to generate ranges of outcomes. Besides the single-point estimates, uncertainty analysis of the $\mathrm{N}$ flows including means, SDs, CVs, 5th and 95th percentiles were provided. More details of uncertainty analysis are provided in the Supplementary Method 4. Moreover, we compared the partial $\mathrm{N}$ flows with previous estimates from China and other cities, which is provided in Supplementary Table 22 and Supplementary Discussion 2.

Assessment of human driver. The Stochastic Impacts by Regression on Population, Affluence, and Technology (STIRPAT) model was used to assess the contributions of socioeconomic factors to changes in anthropogenic $\mathrm{Nr}$ creation. The standard STIRPAT model is facilitated with a logarithm function as a nonlinear transformation function (Eq. (2)). More details of the STIRPAT model are provided in the Supplementary Method 5.

$$
\ln I=a+b \ln P+c \ln A+d \ln T+e
$$

where, $P, A$, and $T$ represent population, affluence, and technology. $b, c$, and $d$ are the coefficients of $P, A$, and T, respectively; $a$ is a constant, and $e$ is the error term. We tested the influence of six related sociological factors (i.e., population, dietary choice, per capita, energy intensity, industrial level, and industrial structure) on anthropogenic $\mathrm{Nr}$ creation and used the Pearson's correlation method to determine the correlations between all factors. Finally, four socioeconomic factors (i.e., population, dietary choice, energy intensity, and industrial level) were selected. 
Dietary choice was defined as the ratio of animal source food to the total food intake. Energy intensity was defined as the energy consumption per unit of GDP (ton SCE per $10^{4}$ yuan). The industrial level was defined as the ratio of $\mathrm{N}_{2}$ converted to $\mathrm{Nr}$ through anthropogenic ammonification to total $\mathrm{Nr}$ creation. Dietary choice (A) was used as a proxy for societal affluence. Energy intensity $\left(\mathrm{T}_{1}\right)$ and industrial level $\left(\mathrm{T}_{2}\right)$ were used as proxies for technology. Here, we revised Eq. (2) by adding these factors, thus producing Eq. (3), and an ordinary least squares (OLS) regression was used to evaluate the variables.

$$
\ln I=a+b \ln P+c \ln A+d_{1} \ln T_{1}+d_{2} \ln T_{2}+e
$$

Reporting summary. Further information on research design is available in the Nature Research Reporting Summary linked to this article.

\section{Data availability}

All relevant data are publicly available in the supplementary materials and online data repositories, and are available from the authors. The sources of activity data, parameters for $\mathrm{N}$ flow analysis are provided in Source Data 1. The source data underlying Figs. 2a-c, $5 \mathrm{a}-\mathrm{d}$ are provided in Source Data 2.

\section{Code availability}

Please see supplementary materials for coupled human-natural urban $\mathrm{N}$ flow modeling, activity data distribution and parameter distribution in Monte Carlo simulation. Further code details can be obtained from the authors upon request.

Received: 18 April 2019; Accepted: 23 January 2020;

Published online: 05 March 2020

\section{References}

1. Schlesinger, W. H. \& Bernhardt, E. S. An analysis of global change. Biogeochemistry (2013).

2. Vitousek, P. M. et al. Human alteration of the global nitrogen cycle: sources and consequences. Ecol. Appl. 7, 737-750 (1997).

3. Galloway, J. N. et al. Nitrogen cycles: past, present and future. Biogeochemistry 70, 153-226 (2004)

4. Erisman, J. W., Sutton, M. A., Galloway, J., Klimont, Z. \& Winiwarter, W. How a century of ammonia synthesis changed the world. Nat. Geosci. 1, 636-639 (2008).

5. Fowler, D. et al. The global nitrogen cycle in the twenty-first century. Philos. Trans. R. Soc. Lond. 368, 20130164 (2013).

6. Lin, T. et al. Managing urban nutrient biogeochemistry for sustainable urbanization. Environ. Pollut. 192, 244-250 (2014).

7. Groffman, P. M., Law, N. L., Belt, K. T., Band, L. E. \& Fisher, G. T. Nitrogen fluxes and retention in urban watershed ecosystems. Ecosystems 7, 393-403 (2004).

8. Kaushal, S. S. et al. Interaction between urbanization and climate variability amplifies watershed nitrate export in Maryland. Environ. Sci. Technol. 42 5872-5878 (2008).

9. Erisman, J. W. et al. Consequences of human modification of the global nitrogen cycle. Philos. Trans. R. Soc. L. B Biol. Sci. 368, 20130116 (2013).

10. Galloway, J. N. et al. Transformation of the nitrogen cycle: recent trends, questions, and potential solutions. Science 320, 889-892 (2008).

11. Galloway, J. N. et al. The nitrogen cascade. Bioscience 53, 341-356 (2003).

12. Schlesinger, W. H. On the fate of anthropogenic nitrogen. Proc. Natl. Acad. Sci. USA 106, 203-208 (2009).

13. Fujimaki, R., Sakai, A. \& Kaneko, N. Ecological risks in anthropogenic disturbance of nitrogen cycles in natural terrestrial ecosystems. Ecol. Res. 24, 955-964 (2009).

14. Gruber, N. \& Galloway, J. N. An Earth-system perspective of the global nitrogen cycle. Nature 451, 293-296 (2008).

15. Cui, S., Shi, Y., Groffman, P. M., Schlesinger, W. H. \& Zhu, Y.-G. Centennialscale analysis of the creation and fate of reactive nitrogen in China (19102010). Proc. Natl. Acad. Sci. USA 110, 2052-2057 (2013).

16. Dong, Y. \& Xu, L. Aggregate risk of reactive nitrogen under anthropogenic disturbance in the Pearl River Delta urban agglomeration. J. Clean. Prod. 211, 490-502 (2019).

17. Han, Y., Li, X. \& Nan, Z. Net anthropogenic nitrogen accumulation in the Beijing metropolitan region. Ecosystems 14, 445-457 (2011).

18. Kaye, J. P., Groffman, P. M., Grimm, N. B., Baker, L. A. \& Pouyat, R. V. A distinct urban biogeochemistry? Trends Ecol. Evol. 21, 192-199 (2006).

19. Alberti, M. et al. Research on coupled human and natural systems (CHANS): approach, challenges, and strategies. Bull. Ecol. Soc. Am. 92, 218-228 (2011).
20. Færge, J., Magid, J. \& Penning De Vries, F. W. T. Urban nutrient balance for Bangkok. Ecol. Modell. 139, 63-74 (2001).

21. Barles, S. Feeding the city: Food consumption and flow of nitrogen, Paris, 1801-1914. Sci. Total Environ. 375, 48-58 (2007).

22. Jennifer, F. Nitrogen balance for the urban food metabolism of Toronto, Canada. Resour. Conserv. Recycl. 52, 74-94 (2008).

23. Zhang, Y., Lu, H., Fath, B. D. \& Zheng, H. Modelling urban nitrogen metabolic processes based on ecological network analysis: A case of study in Beijing, China. Ecol. Modell. 337, 29-38 (2016).

24. Gu, B., Ju, X., Chang, J., Ge, Y. \& Vitousek, P. M. Integrated reactive nitrogen budgets and future trends in China. Proc. Natl. Acad. Sci. USA 112, 8792-8797 (2015).

25. Jiang, S. et al. Enhanced nitrogen and phosphorus flows in a mixed land use basin: drivers and consequences. J. Clean. Prod. 181, 416-425 (2018).

26. Shi, Y., Cui, S., Ju, X., Cai, Z. \& Zhu, Y. G. Impacts of reactive nitrogen on climate change in China. Sci. Rep. 5, 8118 (2015)

27. Guangzhou Municipal Statistics Bureau. Guangzhou Statistical Yearbook (National Bureau of Statistics of China Press, 2016).

28. Environmental Status Bulletin of Guangzhou, Available at: www.gzepb.gov.cn/ (2016).

29. Luo, Z., Hu, S., Chen, D. \& Zhu, B. From production to consumption: a coupled human-environmental nitrogen flow analysis in China. Environ. Sci. Technol. 52, 2025-2035 (2018).

30. Billen, G. et al. Nitrogen use in the global food system: past trends and future trajectories of agronomic performance, pollution, trade, and dietary demand. Environ. Res. Lett. 11, 1-14 (2016).

31. Ma, L. et al. Modeling nutrient flows in the food chain of China. J. Environ Qual. 39, 1279-1289 (2010).

32. Doering, O. et al. Reactive Nitrogen in the United States: an analysis of inputs, flows, consequences, and management options. United States Environ. Prot. Agency (2011).

33. de Vries, W., Leip, A. \& Winiwarter, W. Geographical variation in terrestrial nitrogen budgets across Europe (Cambridge University Press, 2011).

34. Miller, G. Getting minds out of the sewer. Science 337, 679-680 (2012).

35. Zhu, X., Burger, M., Doane, T. A. \& Horwath, W. R. Ammonia oxidation pathways and nitrifier denitrification are significant sources of $\mathrm{N}_{2} \mathrm{O}$ and $\mathrm{NO}$ under low oxygen availability. Proc. Natl. Acad. Sci. USA 110, 6328-6333 (2013).

36. China Air Pollution Prevention and Control Action Plan. Available at: http:// www.gov.cn (2013).

37. Devol, A. H. Denitrification, anammox, and $\mathrm{N}_{2}$ production in marine sediments. Ann. Rev. Mar. Sci. 7, 403 (2015).

38. Li, H., Mu, H. \& Ming, Z. Analysis of China's energy consumption impact factors. Procedia Environ. Sci. 11, 824-830 (2011).

39. Xin, H. et al. A high-resolution ammonia emission inventory in China. Global Biogeochem. Cycles 26 (2012).

40. Davidson, E. A., Keller, M., Erickson, H. E., Verchot, L. V. \& Veldkamp, E. Testing a conceptual model of soil emissions of nitrous and nitric oxides. Bioscience 50, 667-680 (2000).

41. Mosier, A. et al. Closing the global $\mathrm{N}_{2} \mathrm{O}$ budget: nitrous oxide emissions through the agricultural nitrogen cycle. Nutr. Cycl. Agroecosystems 52, 225-248 (1998).

42. Domene, L. A. F. \& Ayres, R. U. Nitrogen's role in industrial systems. J. Ind Ecol. 5, 77-103 (2001)

43. Delucchi, M. Environmental externalities of motor-vehicle use in the US. J. Transp. Econ. Policy 34, 135-168 (2000)

44. Beevers, $\mathrm{S}$. D. et al. Trends in $\mathrm{NOx}$ and $\mathrm{NO}_{2}$ emissions from road traffic in Great Britain. Atmos. Environ. 54, 107-116 (2012).

45. Leach, A. M. et al. A nitrogen footprint model to help consumers understand their role in nitrogen losses to the environment. Environ. Dev. 1, 40-66 (2012).

46. Zhijun, H. et al. Study on degradation patterns of nitrogen in degrading dyes in a plug flow simulation reactor by $\mathrm{TiO}_{2}$. Environ. Enginnering 32, 65-69 (2014).

47. $\mathrm{Gu}, \mathrm{B}$. et al. The role of industrial nitrogen in the global nitrogen biogeochemical cycle. Sci. Rep. 3, 2579 (2013).

48. Qing, D., Keat, S. \& Gersberg, R. M. Municipal solid waste management in China: Status, problems and challenges. J. Environ. Manag. 91, 1623-1633 (2010).

49. Li, H. Synthesis of Azo dyes by Non-diazo-coupling Method (Tianjin University of Technology, 2010).

50. Xue, X. \& Landis, A. E. Eutrophication potential of food consumption patterns. Environ. Sci. Technol. 44, 6450-6456 (2010).

51. Shibata, H. et al. Nitrogen footprints: regional realities and options to reduce nitrogen loss to the environment. Ambio 46, 129-142 (2017).

52. Canfield, D. E., Glazer, A. N. \& Falkowski, P. G. The evolution and future of Earth's nitrogen cycle. Science 330, 192-196 (2010). 
53. Liu, X. et al. Intensification of phosphorus cycling in China since the 1600 s. Proc. Natl. Acad. Sci. USA 113, 2609-2614 (2016).

54. Laner, D., Rechberger, H. \& Astrup, T. Systematic evaluation of uncertainty in material flow analysis. J. Ind. Ecol. 18, 859-870 (2015).

\section{Acknowledgements}

This study was funded by the National Key R\&D Program of China (No. 2016YFC0502800), Funds for Innovative Research Group of the National Natural Science Foundation of China (No. 51721093), Sino-Italian Cooperation of China Natural Science Foundation (CNSC, No. 71861137001) and the Italian Ministry of Foreign Affairs and International Cooperation (MAECI, High Relevance Bilateral Projects).

\section{Author contributions}

L.X. led the study; Y.D. contributed to the model construction, data analysis and writing; with important contributions from Z.Y. developed and improved the model; H.Z. and L.C. assisted with figure preparation and data collection.

\section{Competing interests}

The authors declare no competing interests.

\section{Additional information}

Supplementary information is available for this paper at https://doi.org/10.1038/s41467020-14699-x
Correspondence and requests for materials should be addressed to L.X.

Peer review information Nature Communications thanks Shuang Chen and the other, anonymous, reviewer(s) for their contribution to the peer review of this work.

Reprints and permission information is available at http://www.nature.com/reprints

Publisher's note Springer Nature remains neutral with regard to jurisdictional claims in published maps and institutional affiliations.

(c) (i) Open Access This article is licensed under a Creative Commons Attribution 4.0 International License, which permits use, sharing, adaptation, distribution and reproduction in any medium or format, as long as you give appropriate credit to the original author(s) and the source, provide a link to the Creative Commons license, and indicate if changes were made. The images or other third party material in this article are included in the article's Creative Commons license, unless indicated otherwise in a credit line to the material. If material is not included in the article's Creative Commons license and your intended use is not permitted by statutory regulation or exceeds the permitted use, you will need to obtain permission directly from the copyright holder. To view a copy of this license, visit http://creativecommons.org/ licenses/by/4.0/.

(C) The Author(s) 2020 